\title{
Alterações no Uso e Cobertura da Terra no município de Inocência/MS, nos anos de 2000, 2008 e 2014
}

Changes in Use and Land Cover in the municipality of Inocência/MS, in 2000, 2008 and 2014

Los cambios en el uso y la cubierta terrestre en el municipio de la Inocência/MS, en el 2000, 2008 y 2014

Angélica Estigarribia São Miguel Graduada e Mestre em Geografia pela Universidade Federal de Mato Grosso do Sul, UFMS, Brasil. angelica.esm@hotmail.com

Rafael Brugnolli Medeiros Doutorando em Geografia pela Universidade Federal da Grande Dourados, UFGD, Brasil. rafael_bmedeiros@hotmail.com

Weslen Manari Gomes Mestrando em Geografia pela Universidade Federal de Mato Grosso do Sul, UFMS, Brasil. weslenmanari@hotmali.com 
RESUMO

Uma das intervenções antrópicas que ocorre no Brasil, principalmente no Estado do Mato Grosso do Sul, é a expansão do cultivo de monoculturas, mais precisamente de eucalipto, gerando assim, diversas preocupações que influência nos ambientes naturais. Diante desta premissa, o presente trabalho tem como objetivo identificar as alterações no uso e cobertura da terra em decorrência da expansão do cultivo de eucalipto no município de Inocência/MS, situado na região leste do Estado de Mato Grosso do Sul, nos anos de 2000, 2008 e 2014. Para a análise, utilizou-se das imagens do satélite LandSat 5, sensor TM e do satélite LandSat 8 , sensor OLI, para compreender a evolução do processo de uso e cobertura da terra, com auxílio dos programas Spring ${ }^{\circledR}$ e ArcGis ${ }^{\circledR}$. Os resultados indicaram que a área de pastagem é predominante em todos os anos, o que colabora com a diminuição de áreas florestais. O cultivo de eucalipto está crescendo na região, devido ao aumento das terras de florestas plantadas responsáveis pelas empresas Fibria-MS Celulose Ltda; e Investimentos Florestais S/A - Eldorado Brasil, substituindo as áreas de pastagens e até mesmo áreas de lavouras. Pode-se concluir que as informações obtidas pelos mapeamentos do uso e cobertura da terra evidenciaram a expansão do cultivo de eucalipto e foram classificadas as formas de uso de acordo com a ação antrópica. Portanto possibilitou a caracterização da área, que vem passando por rápidas transformações em seu uso e cobertura da terra, efetivando a necessidade de mais pesquisas voltadas para esta análise.

PALAVRAS CHAVE: Cultivo de eucalipto. Sensoriamento Remoto. Uso e Cobertura da Terra.

\section{Abstract}

One of the anthropic interventions that occurs in Brazil, mainly in the state of Mato Grosso do Sul, it is the expansion of monoculture farming, specifically eucalyptus, thus generating various concerns that influence the natural environment. Given this premise, this paper aims to identify changes in land use and land cover due to the expansion of eucalyptus plantations in the municipality of Inocência/MS, located in the eastern region of the State of Mato Grosso do Sul, in 2000 , 2008 and 2014. For the analysis, we used the Landsat 5 satellite images, TM sensor and satellite Landsat 8, OLI sensor to understand the evolution of land use and land cover process, with the help of programs and Spring ${ }^{\circledast}$ ArcGis $^{\circledR}$. The results indicated that the pasture area is prevalent in every year, which contributes to the reduction of forest areas. Eucalyptus cultivation is growing in the region due to the increase in planted forest land companies responsible for Fibria-MS Celulose Ltda; and Investimentos Florestais S/A - Eldorado Brasil, replacing pasture areas and even areas of crops. It can be concluded that the information obtained by mapping the land use and land cover showed the expansion of eucalyptus plantations and were classified forms of use according to the anthropic action. Therefore enabled the characterization of the area, which is undergoing rapid changes in its use and land cover, effecting the need for more research focused for this analysis.

KEY WORDS: Cultivation of eucalyptus. Remote sensing. Use and Land Cover.

\section{Resumen}

Una de las intervenciones antrópicas que se produce en Brasil, principalmente en el estado de Mato Grosso do Sul, es la expansión de los monocultivos, especialmente de eucalipto, generando diversos problemas que influyen en el entorno natural. Teniendo en cuenta esta premisa, el presente trabajo tiene como objetivo identificar los cambios en el uso y cobertura del suelo debido a la expansión de las plantaciones de eucalipto en el municipio de la Inocência/MS, situada en la región oriental del Estado de Mato Grosso do Sul, en el año 2000 , 2008 y 2014. Para el análisis, se utilizaron las imágenes de satélite Landsat 5 TM, el sensor y el satélite Landsat 8, sensor de OLI para entender la evolución del uso de la tierra y el proceso de cobertura de la tierra, con la ayuda de programas y Spring ${ }^{\circledR}$ $\operatorname{ArcGIS}^{\circledast}$. Los resultados indicaron que la zona de pastos es frecuente en todos los años, lo que contribuye a la reducción de las áreas forestales. Cultivo de eucaliptus está creciendo en la región debido al aumento de compañías de tierras forestales plantados responsables de Fibria-MS Celulose Ltda; y Investimentos Florestais S/A - Eldorado Brasil, la sustitución de las zonas de pasto e incluso zonas de cultivos. Se puede concluir que la información obtenida mediante la asignación del uso y cobertura del suelo mostró la expansión de las plantaciones de eucalipto y se clasificaron las formas de uso de acuerdo con la acción antrópica. Por lo tanto permitido la caracterización de la zona, que está experimentando cambios rápidos en su uso y cobertura del suelo, efectuando la necesidad de más investigación enfocada para este análisis.

PALABRAS CLAVE: El cultivo de eucalipto. Detección remota. Uso y Cobertura de la Tierra. 


\section{Introdução}

O meio ambiente apresenta uma singular competência de regeneração e recuperação contra eventuais desequilíbrios, sejam eles descontínuos ou localizados, muitos dos quais gerados pela própria natureza, no entanto, a agressão originada pelo homem e seu desenvolvimento econômico desordenado vem sendo contínuo, não oferecendo oportunidade, tampouco, tempo para a regeneração destes ecossistemas.

Uma das intervenções antrópicas que ocorre no Brasil, principalmente na região leste do Estado do Mato Grosso do Sul, é a expansão do cultivo de monoculturas, mais precisamente de eucalipto, pertencentes às empresas Fibria MS Celulose Ltda; e Eldorado Brasil Celulose S.A. O contexto atual no Brasil, sobre o avanço da produção de eucalipto, se dá na década de $60 \mathrm{e}$ 70 devido à introdução de alguns incentivos fiscais para a aplicação no mercado acionário, dentre os quais se destacam o Fundo 157, criados pelo Decreto Lei no 157, de 10/02/1967. O Fundo 157 era uma opção fornecida aos contribuintes de utilizar parte do imposto de renda em aquisição de quotas de fundos administrados por instituições financeiras de livre escolha do aplicador (PORTAL DO INVESTIDOR, s/d).

O eucalipto é uma árvore nativa da Austrália, do Timor e da Indonésia, sendo considerada uma espécie exótica em todas as outras partes do Mundo. Sua implantação no Brasil se deu por meio de Frederico de Albuquerque, no ano de 1968, no estado do Rio Grande do Sul. No estado do Rio de Janeiro um dos maiores propagadores da espécie pelo país, foi Pereira da Fonseca que realizou grandes plantações, com variadas espécies do gênero eucalyptus (ANDRADE, 1918).

O mesmo leva aproximadamente sete anos até ser colhido e requer poucas ações do homem sobre o solo. Ele pode ser cultivado em terrenos de baixa fertilidade natural e não exigem muitos nutrientes e defensivos agrícolas em comparação com outras culturas (FIBRIA/MS, 2014).

Entretanto, o aumento nas áreas de plantio do eucalipto e o crescimento de empresas que trabalham neste setor, como as de celulose e papel, têm fortalecido os questionamentos feitos em relação à ocupação de terras e os impactos que estes empreendimentos podem gerar em aspectos sociais, econômicos e ambientais.

Diante disto, o que se observa é uma excessiva pressão do sistema produtivo sobre os recursos naturais, buscando a obtenção de matéria prima que é empregada na produção de bens, sendo utilizados no crescimento econômico. Esse desenvolvimento gera capital, mas em contrapartida, além de rejeitos e efluentes, gera uma degradação ao meio ambiente, muito dos quais irreversíveis (ALMEIDA et al 1993).

Segundo Oliveira (2012), esse desenvolvimento econômico por sua vez, tem se mostrado influenciado pelo avanço tecnológico e informativo. A partir desses avanços, indústrias do setor privado levam em consideração em seus processos produtivos os custos gerados sobre seus produtos acabados, a exemplo disso são as empresas que para um menor gasto e maior lucratividade, estão se instalando em locais estratégicos, visando ficarem mais próximas de suas matérias-primas e/ou recursos naturais. 
As modificações constantes no uso e cobertura da terra, ocasionadas por estes processos produtivos, causam alterações em um ritmo mais acelerado ao meio ambiente do que o impresso pela natureza, gerando uma constante dinâmica, proporcionando um desequilíbrio nos ecossistemas, principalmente, quando não se conhece a área e não é realizado um manejo adequado do solo.

Tanto é que ao longo das últimas décadas, ações corretivas e de prevenção surgiram em função da discussão sobre a importância em se promover o desenvolvimento econômico e social aliado à proteção ambiental, onde a inclusão de medidas de disciplinamento, principalmente do uso e cobertura da terra e da apropriação dos recursos naturais, assumem um papel fundamental (BEZERRA, 2008).

Uma das regiões que mais cresce neste setor de celulose e papel é o leste do Mato Grosso do Sul e segundo os dados da REFLORE-MS - Associação Sul-Mato-Grossense de Produtores e Consumidores de Florestas Plantadas apontam que nos últimos seis anos, a área destinada ao cultivo do eucalipto no estado cresceu $475 \%$. A expansão foi motivada, principalmente, depois que duas indústrias de celulose foram instaladas na região leste de Mato Grosso do Sul. Hoje são aproximadamente 750 mil hectares destinados ao cultivo de eucalipto no estado, mas esse número deve aumentar, a previsão é que passem de 800 mil hectares até o fim do ano.

Em 1988, a empresa Chamflora Três Lagoas Agroflorestal Ltda; e International Paper do Brasil Ltda (IP) chegou ao estado de Mato Grosso do Sul tornando-se referência em tecnologia, modelo de gestão, inovadora em desenvolvimento operacional, qualidade de florestas e mãode-obra especializada. Segundo Fernandes (2013), em 2009 e 2012 o município de Três Lagoas recebeu mais duas empresas de celulose a Fibria MS Celulose Ltda; e Eldorado Brasil Celulose S.A; ambas responsáveis pelo aumento da produção de florestas plantadas no Brasil.

Um grande exemplo deste aumento ocorreu em 2011, que registrou o maior crescimento proporcional de área de floresta plantada, segundo o Anuário Estatístico da ABRAF Associação Brasileira de Floresta Plantada, o estado de Mato Grosso do Sul registrou aproximadamente $597,13 \mathrm{ha}$ em áreas consolidadas com florestas plantadas.

Contudo, buscando analisar as alterações no uso e cobertura da terra em decorrência da expansão do setor florestal, esta pesquisa, observou o processo de expansão do eucalipto no município de Inocência, que está situado entre as coordenadas geográficas latitude $19^{\circ} 43^{\prime}$ 4 " sul e longitude $51^{\circ} 55^{\prime} 15^{\prime \prime}$ oeste, conforme mostra a Figura 1. 


\section{da Alta Paulista}

Figura 1: Mapa de localização do Município de Inocência/MS

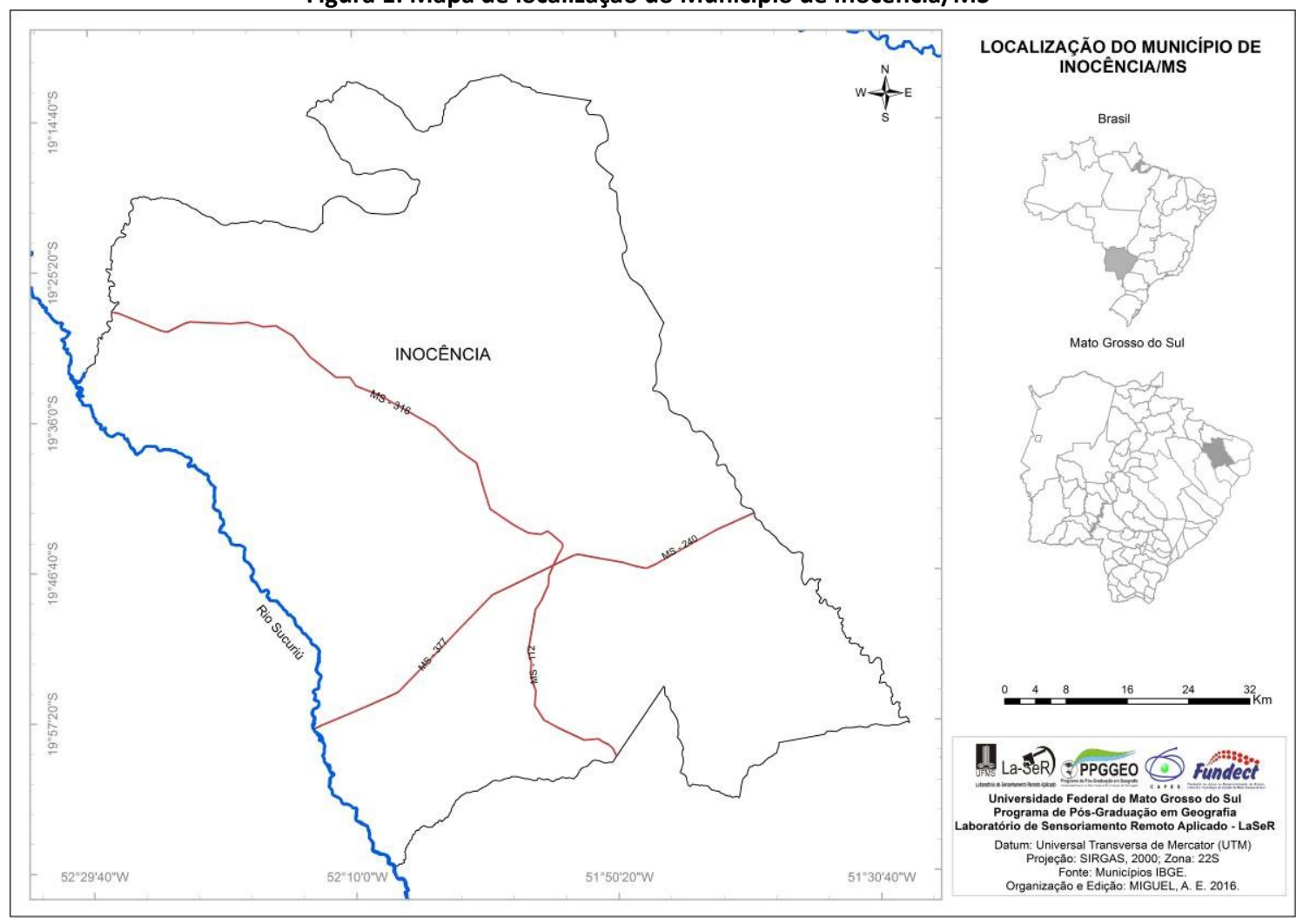

OBJETIVO

Esta pesquisa tem como objetivo analisar as alterações no uso e cobertura da terra em decorrência da expansão do cultivo de eucalipto no município de Inocência nos anos de 2000, 2008 e 2014. Para atingi-lo, recorrerá à utilização de técnicas de Sensoriamento Remoto, através do emprego de SIG - Sistema de Informações Geográficas.

\section{METODOLOGIA}

Nesta pesquisa buscou a elaboração de um bando de dados em ambiente SIG, sendo utilizados os softwares Spring ${ }^{\bullet}$ 5.0.6 e ArcGis ${ }^{\bullet} 10$, para elaboração da classificação do uso e cobertura da terra do município de Inocência/MS nos anos de 2000, 2008 e 2014, para analisar as alterações da expansão do cultivo de eucalipto.

Para a elaboração do mapa de uso e cobertura da terra foi feita uma interpretação de imagens do satélite Landsat TM 5, bandas 3, 4 e 5 do mês de março do ano de 2000 e 2008, adquiridas gratuitamente no site do INPE - Instituto Nacional de Pesquisas Espaciais e do satélite Landsat OLI 8, bandas 4, 5 e 6 do ano de 2014 adquiridas no site Earth Explorer do Serviço Geológico dos Estados Unidos.

As imagens dos anos de 2000 e 2008 foram importadas e georreferenciadas por meio de pontos de controle passíveis de identificação na imagem, sendo que a imagem do ano de 2014 


\section{da Alta Paulista}

já vem georreferenciada. A fim de melhorar a qualidade da imagem utilizou o contraste por meio de equalização do histograma e linear. A manipulação do contraste consiste numa transferência radiométrica em cada "pixel", com o objetivo de aumentar a discriminação visual entre os objetos presentes na imagem. Realiza-se a operação ponto a ponto, independentemente da vizinhança (DPI/INPE, 2006). A partir deste contraste foi salva a imagem sintética 5 das imagens Landsat TM 5 e Landsat OLI 8, classificando o uso do solo, por meio de classificação por histograma, onde são definidos os temas para cada objeto encontrado na imagem.

As definições das classes do uso e cobertura da terra dos três diferentes anos foram: cultivo de eucalipto, lavouras, área florestal, pastagem, área descoberta, área urbanizada, solo úmido e água. Na classe temática cultivos de eucalipto foram adquiridos amostra de toda área destinada ao plantio de eucalipto. As classes lavouras referem-se às áreas de lavouras temporárias de plantio de cana de açúcar e outras culturas. A classe temática área florestal é referente às áreas de reserva legal e matas ciliares. Na classe temática pastagem foi caracterizada pela presença de gramíneas destinadas a criação do gado de corte ou apenas pastagem. Na categoria área urbanizada foi delimitado a cidade de Inocência/MS. Com relação à classe de solo úmido, são áreas de várzeas ou pontos de alagamentos, sendo encontrada ao longo de todas as áreas próximas dos cursos d'água.

Por fim a imagem classificada no Spring foi importada para o ArcGis ${ }^{\bullet} 10$, para elaboração do layout do mapa, na interpretação de imagens de satélites diversos fatores devem ser levados em consideração como, por exemplo, o nível de experiência do analista, as características das bandas utilizadas pelo satélite utilizado no imageamento e principalmente, o conhecimento da área de estudo. Na verdade, quanto maior é o conhecimento sobre a área de estudo, maior é a qualidade de informações que podem obter (FLORENZANO, 2007, p.43).

\section{RESULTADOS}

Foram analisados os mapas de uso e cobertura da terra do município de Inocência/MS nos anos de 2000, 2008 e 2014, como mostra a Tabela 1 com os dados já calculados em km² e \% e Figura 2 e 3. Dessa forma, a elaboração de uma comparação entre os anos analisados se torna importante ferramenta para o entendimento das mudanças ocorridas no município.

Com base nas informaçoes retiradas da Tabela 1, as áreas destinadas à pastagens, mostraram ser predominantes na área em todos os anos de análise, sendo característico na região, no ano de 2000 e 2008 ocupou uma área de $4237,12 \mathrm{~km}^{2}$ e $4214,78 \mathrm{~km}^{2}$ respectivamente alcançando $73 \%$ da área total, no ano de 2014 teve uma redução de $4 \%$ obtendo uma área de $3980,27 \mathrm{~km}^{2}$. 


\section{Fórum Ambiental}

\section{da Alta Paulista}

Tabela 1: Evolução do Uso e Cobertura da Terra no Município de Inocência/MS, nos anos de 2000, 2008 e 2014

\begin{tabular}{|c|c|c|c|c|c|c|c|c|c|c|}
\hline \multirow[b]{2}{*}{ Classes } & \multicolumn{2}{|c|}{2000} & \multicolumn{4}{|c|}{2008} & \multicolumn{4}{|c|}{2014} \\
\hline & $\begin{array}{l}\text { Área } \\
\left(\mathrm{km}^{2}\right)\end{array}$ & $\begin{array}{c}\text { Área } \\
\text { (\%) }\end{array}$ & $\begin{array}{l}\text { Área } \\
\left(\mathrm{km}^{2}\right)\end{array}$ & $\begin{array}{c}\text { Desvio } \\
\left(\mathrm{km}^{2}\right)\end{array}$ & $\begin{array}{c}\text { Área } \\
\text { (\%) }\end{array}$ & $\begin{array}{c}\text { Desvio } \\
\text { (\%) }\end{array}$ & $\begin{array}{l}\text { Área } \\
\left(\mathrm{km}^{2}\right)\end{array}$ & $\begin{array}{c}\text { Desvio } \\
\left(\mathbf{k m}^{2}\right)\end{array}$ & $\begin{array}{c}\text { Área } \\
\text { (\%) }\end{array}$ & $\begin{array}{c}\text { Desvio } \\
\text { (\%) }\end{array}$ \\
\hline Área Descoberta & 20,45 & 0,35 & 20,45 & 0,00 & 0,35 & 0,00 & 21,47 & 1,02 & 0,37 & 0,02 \\
\hline Área Florestal & 1398,94 & 24,23 & 1390,17 & $-8,77$ & 24,08 & $-0,15$ & 1359,34 & $-30,83$ & 23,55 & $-0,53$ \\
\hline Área Urbanizada & 1,77 & 0,03 & 2,78 & 1,01 & 0,05 & 0,02 & 4,84 & 2,06 & 0,08 & 0,04 \\
\hline Corpos d’Água & 5,79 & 0,10 & 5,59 & $-0,20$ & 0,10 & 0,00 & 5,39 & $-0,20$ & 0,09 & 0,00 \\
\hline Cultivo de Eucalipto & 0,00 & 0,00 & 0,00 & 0,00 & 0,00 & 0,00 & 291,46 & 291,46 & 5,05 & 5,05 \\
\hline Lavouras & 1,33 & 0,02 & 21,45 & 0,00 & 0,02 & 0,00 & 3,33 & 2,00 & 0,06 & 0,03 \\
\hline Pastagem & 4237,12 & 73,39 & 4214,78 & $-22,34$ & 73,01 & $-0,39$ & 3980,27 & $-234,51$ & 68,94 & $-4,06$ \\
\hline Solo Úmido & 107,72 & 1,87 & 138,02 & 30,30 & 2,39 & 0,52 & 107,02 & $-31,00$ & 1,85 & $-0,54$ \\
\hline TOTAL & 5773,12 & 100,00 & 5773,12 & & 100,00 & & 5773,12 & & 100,00 & \\
\hline
\end{tabular}

Figura 2: Mapa de Uso e Cobertura da Terra no Município de Inocência/MS, nos anos de 2000, 2008 e 2014.

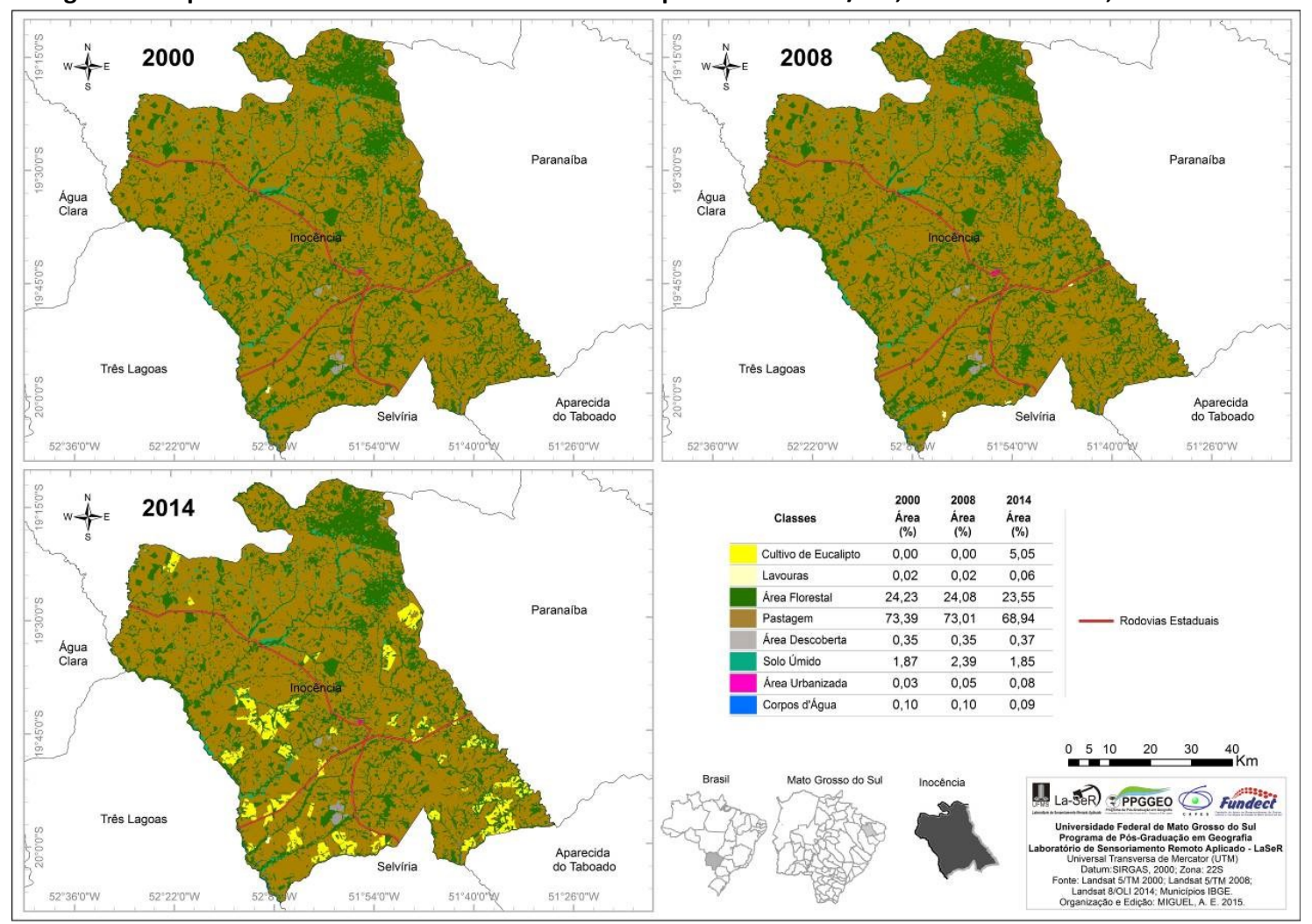




\section{da Alta Paulista}

Figura 3: Gráfico da Evolução do Uso e Cobertura da Terra no Município de Inocência/MS, nos anos de 2000, 2008 e 2014.

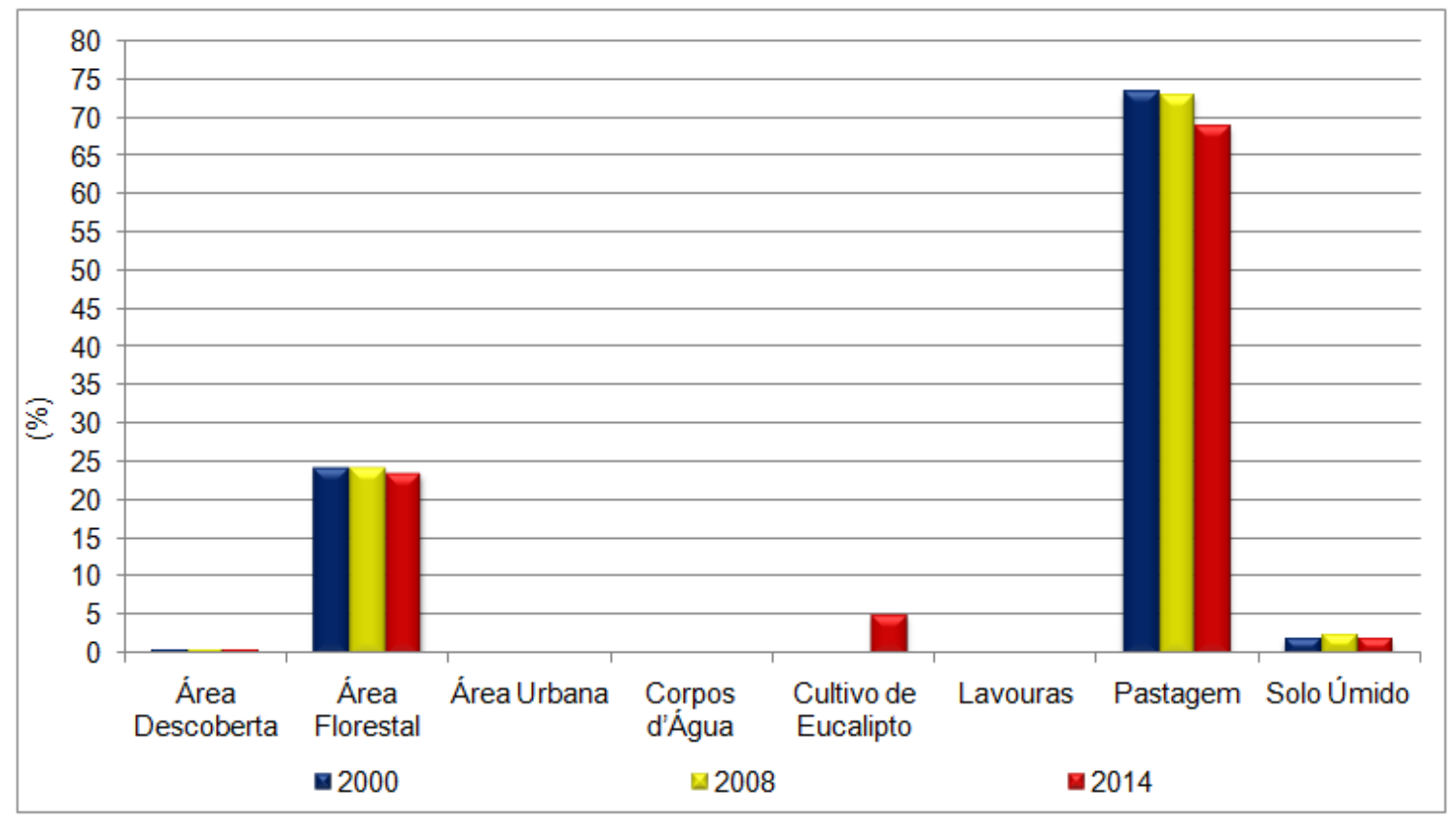

Após a elaboração da análise, verificou-se que no ano de 2000 a categoria Área Urbanizada, que corresponde à área urbana do município de Inocência/MS, representando uma área de $1,77 \mathrm{~km}^{2}$, evoluindo nos dois últimos anos analisados, passando a ocupar em 2014 uma área de $4,84 \mathrm{~km}^{2}$. Esta análise mostra uma tendência das cidades atualmente, elevando não apenas seu perímetro urbano, bem como sua população.

A Área Florestal, Figura 4, apresentou um total de $1398,94 \mathrm{~km}^{2}$, no ano de 2000 , sendo a segunda maior classe mapeada, é importante frisar, que a vegetação de cerrado que recobrira as terras da região, hoje se restringe a pequenas reservas esparsas, ou nas proximidades das matas ciliares, já não sendo possível seu enquadramento nesta classe de uso. Em 2008 obteve uma área de $1390,17 \mathrm{~km}^{2}$, o que significa que teve uma diminuição de $8,77 \mathrm{~km}^{2}$, reduzindo novamente em 2014, apresentando uma área de $1359,34 \mathrm{~km}^{2}$, esta redução causa uma preocupação, seja pela quantidade como também pelo desequilíbrio que a falta dessa vegetação traz ao ambiente.

Sendo necessário levar em consideração, que todas as áreas florestais estão bem representadas ao longo dos cursos fluviais deste município, sendo que o cultivo de eucalipto não adentra estas terras, importante fator, pois quanto maior sua vegetação e a cobertura que proteja o solo, menor quantidade de sedimentos serão carreados, consequentemente, poderá acarretar em melhora na quantidade e qualidade das águas superficiais, das bacias hidrográficas que estão inseridas no município de Inocência/MS. 


\section{da Alta Paulista}

Figura 4: Área Florestal, encontrada em marchas dispersas ao longo de todo o município de Inocência/MS.

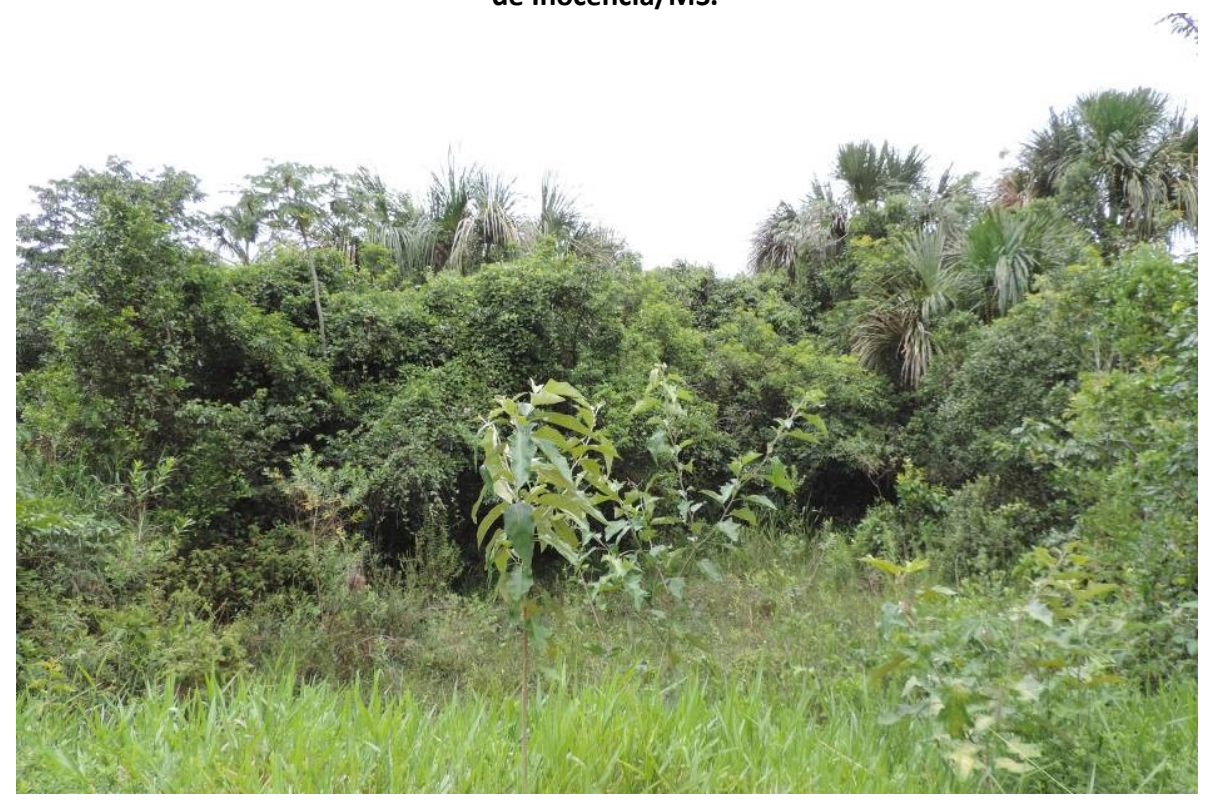

De acordo com as analises, o cultivo de eucalipto, Figura 5, foi constatado apenas no ano de 2014, abrangendo uma área de $291,46 \mathrm{~km}^{2}$, essas áreas é de responsabilidade da empresa Eldorado Brasil Celulose S.A. Estas áreas destinadas ao cultivo de eucalipto cresceram com o passar dos anos analisados.

Mostrando assim, uma tendência para os demais anos, partindo para a necessidade de constantes análises destas áreas, visto que, o aumento no uso e cobertura da terra com os plantios de espécies exóticas, como o Eucalyptus grandis e Eucalyptus urophylla, ou cruzamentos, manipulados geneticamente, tem gerado benefícios e consequências questionáveis.

Tanto é que, segundo Bueno et. al. (2005), este tipo de monocultura é capaz de introduzir impactos à biodiversidade e ao meio ambiente como um todo, entretanto, promove a formação de novas estruturas e o restabelecimento das funções dos ecossistemas mais degradados, podendo ser utilizadas como formas de reflorestamento. 


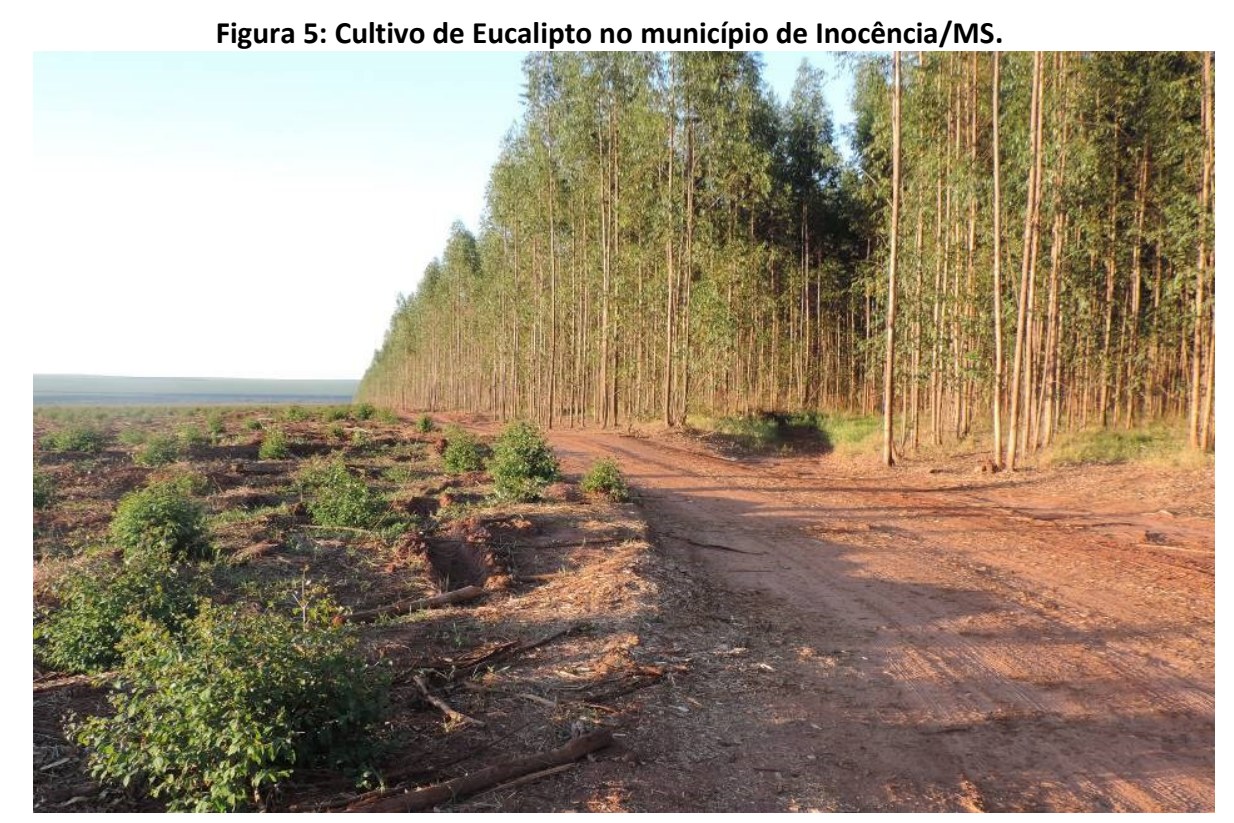

As Lavouras representaram apenas em 2008 , sendo uma área de $21,45 \mathrm{~km}^{2}$, se mantendo na mesma proporção em 2014, essas lavouras é representadas por plantações de cana-de-açúcar. As áreas de Corpos d'Água obtiveram uma área $5,79 \mathrm{~km}^{2}$ no ano de 2000 , nos outros anos passou a ocupar $5,59 \mathrm{~km}^{2}$ e $5,39 \mathrm{~km}^{2}$ nos anos de 2008 e 2014 respectivamente. Esse valor não é exato, pois o topo das árvores máscara o curso da água, dificultando assim o processamento digital para o pesquisador.

A classe Áreas Descobertas, que corresponde a áreas com solo exposto, como foi explicado, está relacionada com a classe de Lavouras e Cultivo de Eucalipto, pois grande parte de suas terras, são de áreas utilizadas para replantio destas culturas, portando, no ano de 2000 apresentava uma área de $20,45 \mathrm{~km}^{2}$, se mantendo com o mesmo valor no ano de 2008 e no ano de 2014 teve um aumento passando a ocupar $21,47 \mathrm{~km}^{2}$.

As áreas referente ao Solo Úmido, são áreas de planícies encontradas entorno do corpo d'água, no ano de 2000 ocupou uma área de 107,72km², aumentando sua área em 2008 para $138,02 \mathrm{~km}^{2}$ e em 2014 representou uma área de 1107,02 km², essa classe sofre alteração em épocas de estação seca e chuvosa.

\section{CONCLUSÕES}

As técnicas de sensoriamento remoto e geoprocessamento possibilitaram a identificação da evolução do uso e cobertura da terra no município de Inocência/MS, através dos programas ArcGis 10 e Spring 5.2.3 em um Sistema de Informação Geográfica proporcionando um resultado satisfatório.

Nota-se que existe uma extensa área voltada para pastagens e grande parte dessa área utilizada para pecuária, como a grande entrada do cultivo de eucalipto no ano de 2014, 
impulsionado pelo aumento da produção das indústrias da Fibria MS Celulose Ltda; e Eldorado Brasil S.A; localizadas no município de Três Lagoas/MS.

Através dos mapas, pode-se analisar se há decréscimo de área florestal, sendo observado que essas áreas estão sendo ocupadas por áreas de lavouras e cultivo de eucalipto e até mesmo por novas áreas de pastagens.

Por fim, os estudos voltados do uso e cobertura da terra possibilitam um detalhamento prévio do meio físico da área estudada. Esse estudo servirá como base para elaboração de novos estudos ambientais, sendo que a análise sobre a expansão do cultivo de eucalipto no estado de Mato Grosso do Sul, ainda se mostra nova, apontando para a necessidade de novas pesquisas.

\section{REFERÊNCIAS BIBLIOGRÁFICAS}

ABRAF - Associação Brasileira deProdutores de Florestas Plantada . Anuário estatístico ABRAF 2013 ano base 2012 / ABRAF. - Brasília: 2013. 148 p. : il. color; $21 \mathrm{~cm}$.

ALMEIDA, J.R. DE; ORSOLON, A.M.; MALHEIROS, T.M.; PEREIRA, S.R.B.; AMARAL, F. \& SILVA, D.M. Planejamento ambiental: caminho para participação popular e gestão ambiental para nosso futuro comum, uma necessidade, um desafio. Ed. Thex Ltda/Biblioteca Estácio de Sá, Rio de Janeiro,1993, 154p

ANDRADE, E. N. de; VECCHI, O. Os Eucalyptos: Sua Cultura e Exploração. São Paulo: Typhographia Brazil de Rothschild \& Comp, 1918.

BEZERRA, A. F. Qualidade Ambiental Urbana do Distrito de Baeta Neves, Município de São Bernardo do Campo (SP). São Paulo: USP, 2008.

FIBRIA/MS. 2014. Plano de Manejo: Unidade Florestal MS - Três Lagoas. 7ạ edição, 2014.

OLIVEIRA, G. H. de. Dinâmicas Geoambientais: desenvolvimento econômico e sustentabilidade ambiental. Revista Eletrônica da Associação dos Geógrafos Brasileiros - Seção Três LagoasMS, no15, p.152-153, 2012.

PORTAL DO INVESTIDOR. Fundo 157. Disponível em: <http://www.investidor.gov.br/>. Acesso em: 15 mar. 2014.

REFLORE-MS. Expansão das florestas plantadas no brasil. Disponível em: < http://www.reflore.com.br//blogs/expansao-das-florestas-plantadas-no-brasil> Acesso em: 02 de Setembro de 2014. 